\title{
Presence of Concomitant Systemic Cancer is Not Associated with Worse Functional Long-Term Outcome in Patients with Intracerebral Hemorrhage
}

\author{
Maximilian I. Sprügel ${ }^{\mathrm{a}}$ Joji B. Kuramatsu ${ }^{\mathrm{a}}$ Stefan T. Gerner ${ }^{\mathrm{a}}$ \\ Jochen A. Sembill ${ }^{a}$ Julius Hartwich ${ }^{a}$ Antje Giede-Jeppe ${ }^{a}$ Dominik Madžar ${ }^{a}$ \\ Vanessa D. Beuscher ${ }^{a}$ Philip Hoelter $^{b}$ Hannes Lücking ${ }^{b}$ Tobias Struffert $^{b}$ \\ Stefan Schwab ${ }^{a}$ Hagen B. Huttner ${ }^{a}$ \\ ${ }^{a}$ Department of Neurology, and ${ }^{b}$ Department of Neuroradiology, University Hospital Erlangen, Erlangen, Germany
}

\section{Keywords \\ Intracerebral hemorrhage · Intracranial hemorrhage · \\ Cancer · Malignancy · Critical care · Prognosis · Imaging}

\begin{abstract}
Background: Data on clinical characteristics and outcome of patients with intracerebral hemorrhage $(\mathrm{ICH})$ and concomitant systemic cancer disease are very limited. Methods: Nine hundred and seventy three consecutive primary ICH patients were analyzed using our prospective institutional registry over a period of 9 years (2006-2014). We compared clinical and radiological parameters as well as outcome - scored using the modified Rankin Scale (mRS) and analyzed in a dichotomized fashion as favorable outcome ( $\mathrm{mRS}=0-3)$ and unfavorable outcome ( $\mathrm{mRS}=4-6$ ) - of ICH patients with and without cancer. Relevant imbalances in baseline clinical and radiological characteristics were adjusted using propensity score (PS) matching. Results: Prevalence of systemic cancer among patients with ICH was $8.5 \%$ (83/973). ICH patients with cancer were older (77 [70-82] vs. 72 [63-80] years; $p=$ 0.002 ), had more often prior renal dysfunction (19/83 [22.9\%] vs.107/890 [12.0\%]; $p=0.005)$, and smaller hemorrhage volumes (10.1 [4.8-24.3] vs. 15.3 [5.4-42.9] $\mathrm{mL} ; p=0.017)$. After
\end{abstract}

\section{KARGER}

(c) 2017 S. Karger AG, Basel

E-Mail karger@karger.com

www.karger.com/ced
PS-matching there were no significant differences neither in mortality nor in functional outcome both at 3 months (mortality: 33/81 [40.7\%] vs. 55/158 [34.8\%]; $p=0.368 ; \mathrm{mRS}=0-3$ : $28 / 81$ [34.6\%] vs. $52 / 158$ [32.9\%]; $p=0.797$ ) and 12 months (mortality: $39 / 78$ [50.0\%] vs. 70/150 [46.7\%]; $p=0.633 ; \mathrm{mRS}=$ $0-3: 25 / 78$ [32.1\%] vs. 53/150 [35.3\%]; $p=0.620$ ) among patients with and without concomitant systemic cancer. $\mathrm{ICH}$ volume tended to be highest in patients with hematooncologic malignancy and smallest in urothelial cancer. Conclusions: Patients with ICH and concomitant systemic cancer on average are older; however, they show smaller ICH volumes compared to patients without cancer. Yet, mortality and functional outcome is not different in ICH patients with and without cancer. Thus, the clinical history or the de novo diagnosis of concomitant malignancies in $\mathrm{ICH}$ patients should not lead to unjustified treatment restrictions.

두 2017 S. Karger AG, Basel

\section{Introduction}

Cerebrovascular disease is the leading cause of acquired disability [1]. Specifically in Western Countries, alongside with an ageing population, the incidence of 
stroke is expected to significantly increase within a few decades [2]. Notably, spontaneous intracerebral hemorrhage (ICH) is related to significant morbidity and mortality [3], harboring implications regarding the socioeconomic burden related to functional long-term outcome [1].

Besides vascular diseases, cancer represents the major cause for death worldwide [4]. Also linked to age, both population-based incidence and prevalence rates of cancer will likewise increase [5]. Given several selfsame risk factors related to stroke and cancer, both diseases may affect patients concomitantly [6-8]. Yet, there are very limited data - all with substantial methodological shortcomings [9-11] - on the interaction between ICH and cancer in relation to functional outcome.

Intuitively, stroke physicians would prognosticate the functional outcome to be worse in those $\mathrm{ICH}$ patients with concomitant cancer diagnoses [12]. However, a solid clinical study - with a sound statistical approach accounting for imbalances in baseline parameters - is missing.

This study (i) investigated the prevalence of concomitant systemic cancer disease among patients with $\mathrm{ICH}$, (ii) assessed clinical and radiological characteristics of ICH cancer-patients, and (iii) explored the clinical relevance of coincidental cancer regarding functional longterm outcome after ICH.

\section{Methods}

\section{Patient Selection}

All consecutive patients with ICH admitted to the Department of Neurology, University Hospital Erlangen, Germany, over a period of 9 years (2006-2014) were prospectively entered into our institutional registry $(n=1.134)$. For this observational study, we excluded 161 patients because of secondary ICH etiologies $(n=$ 112; for example, trauma, aneurysm, intratumoral hemorrhage, or arteriovenous malformation), missing data $(n=36)$, and refused consent $(n=13)$. The study was approved by the institutional review board and informed consent of the patients or legal representatives was obtained.

\section{Data Acquisition}

Demographics (age, gender), preexisting status (modified Rankin Scale [mRS] [13] prior to ICH, comorbidities), medication, admission status (blood pressure, Glasgow Coma Scale, National Institutes of Health Stroke Scale [NIHSS], and ICH Score), in-hospital parameters (length of stay, in-hospital mortality, incidence of pneumonia, sepsis, mechanical ventilation and placement of external ventricular drainage) as well as laboratory data (international normalized ratio [INR], activated partial thromboplastin time, count of leucocytes/thrombocytes, hemoglobin, C-reactive protein, creatinine, troponin) were retrieved from medical records and institutional databases. Liver dysfunction (chronic hepatic disease or Bilirubin $>2 \times$ or AST/ALT/AP $>3 \times$ upper limit of normal) and renal dysfunction (glomerular filtration rate $<60 \mathrm{~mL} /$ $\min / 1.73 \mathrm{~m}^{2}$ ) were defined according to international criteria [14, 15]. We retrospectively reviewed the medical charts of all included $973 \mathrm{ICH}$ patients for diagnosis of at least one malignant cancer. In patients with more than one cancer type, we scored the cancer type that - according to international criteria (National Comprehensive Cancer Network Guidelines) - was graded as more malignant with shorter survival times $[9,11]$. Active cancer was defined as diagnosed or treated within the previous 6 months or reported as recurrent/metastatic cancer, while other malignancies were defined as nonactive [16]. The type of treatment (operation/radio-/ chemotherapy) and the period between the time that the tumor was diagnosed and the onset time of ICH were assessed.

\section{Outcome Measurement}

Mortality and functional outcome (dichotomized into favorable outcome, defined as mRS between 0 and 3, and unfavorable outcome, $\mathrm{mRS}=4-6$, as described previously in randomized ICH trials $[17,18])$ were evaluated at 3 months (short-term outcome) and at 12 months (long-term outcome) after ICH onset and were obtained by physicians trained and certified for outcome evaluation [19]. The assessment tool was a standardized mailed questionnaire; if the questionnaire was not returned within 4 weeks, then a semi-structured telephone interview was conducted.

\section{Imaging}

$\mathrm{ICH}$ was diagnosed by multislice computed tomography (SOMATOM Volume Zoom or SOMATOM Definition AS+; Siemens Healthcare, Forchheim, Germany) or 1.5 Tesla magnetic resonance imaging (MAGNETOM Sonata or MAGNETOM Aera; Siemens Healthcare, Erlangen, Germany). Two neuroradiologists blinded to clinical data - independently evaluated initial and follow-up imaging, including eventual MRI during the follow-up period performed to exclude secondary $\mathrm{ICH}$ etiology after ICH resorption. Patients with intracranial lesions were included only if imaging showed hemorrhage in a brain area topographically distant to the tumorous lesion. ICH volume was assessed using the $\mathrm{ABC} / 2$ formula [20] or the $\mathrm{ABC} / 3$ formula [21] and adjusted to imaging modalities [22]. Hematoma enlargement was defined as a relative volume increase of more than $33 \%$ from initial to followup imaging [23]. The site of hemorrhage and ventricular involvement were scored as described earlier [24].

\section{Statistical Analysis}

Data were analyzed using SPSS version 20.0 (SPSS Inc) and $\mathrm{R}$ version 2.12.0 ( $\mathrm{R}$ project). We performed 2-sided statistical tests and set the significance level at $\alpha=0.05$. Frequency distribution of categorical variables (presented as total number and frequency in brackets) was compared by Pearsons- $\chi^{2}$ and the Fisher's exact test. Data of continuous variables (presented as median and interquartile range because of non-normally distributed) were analyzed using the Mann-Whitney U test. A total of 16 patients were excluded from outcome analysis only as there were no follow-up information on outcome measures available (ICH with cancer: $2 / 83$ [2.4\%] after 3 months and 5/83 [6.0\%] after 12 months; ICH without cancer: $3 / 161$ [1.9\%] after 3 months and 11/161 [6.8\%] after 12 months). Online supplementary Table 1 (for all online suppl. material, see www.karger.com/doi/10.1159/000479075) 
displays the baseline characteristics of these patients who were lost to follow-up. To properly compare the functional outcome of ICH patients with and without cancer, we performed a propensity score (PS) matching using a balanced, parallel, 1:1 ratio nearest-neighbor approach [25]. We adjusted for relevant imbalances of baseline parameters relating to demographics, comorbidities, admission status, and radiological ICH characteristics (i.e., $p<$ $0.10)[26]$.

\section{Results}

Prevalence of Cancer and Baseline Characteristics

Overall, of the 973 included patients with ICH, 83 patients $(8.5 \%)$ had a diagnosis of at least one type of cancer (Table 1). ICH patients with cancer were older (77 [70$82]$ vs. 72 [63-80] years; $p=0.002)$, and had more often preexisting renal dysfunction (19/83 [22.9\%] vs. 107/890 [12.0\%], $p=0.005)$ with correspondingly higher creatinine levels at admission (90.17 [65.86-113.15] vs. 77.79 [63.65-95.69] $\mu \mathrm{mol} / \mathrm{L} ; p=0.006)$. As compared to patients without cancer, those with concomitant cancer diagnoses showed smaller ICH volumes (10.1 [4.8-24.3] vs. 15.3 [5.4-42.9] mL; $p=0.017)$. Notably, the clinical admission status was comparable and there were no other significant differences in comorbidities, admission status, complications during hospital stay, or hematoma characteristics (Table 1). Patients with active cancer also showed more pre-existing renal dysfunction, but presented more frequently with liver dysfunction and higher C-reactive protein levels on admission (online suppl. Table 2).

\section{Cancer-Associated Parameters}

Among ICH patients with cancer, more than 30 cancer types were evident (Table 2), categorized into solid tumors $(71 / 83 ; 85.5 \%)$, primary brain tumors $(2 / 83 ; 2.4 \%)$, and hematooncologic malignancies $(10 / 83 ; 12.0 \%)$. An active cancer was present in 29 out of 83 (34.9\%), and 8 out of 83 (9.6\%) showed systemic metastases. The median time from cancer diagnosis to ICH was 62 months $(1,865$ days [537-4,668]). Out of $83 \mathrm{ICH}$ cancer-patients, 26 $(31.3 \%)$ received prior chemotherapy, 21 (25.3\%) received radiotherapy, and $66(79.5 \%)$ underwent tumor surgery.

ICH volume tended to be the highest in patients with hematooncologic malignancies (26.5 [6.4-44.6] vs. 9.5 [4.7-21.9] $\mathrm{mL} ; p=0.166)$ and smallest with urothelial cancer (1.0 [0.6-13.8] vs. 10.5 [5.4-27.8] $\mathrm{mL} ; p=0.076)$. Colorectal cancer patients had larger ICH volumes (20.9 [10.9-100.8] vs. 9.3 [4.0-21.8] mL; $p=0.012$ ) compared to patients with other cancer types. After exclusion of an- ticoagulated patients, colorectal cancer patients still presented with larger ICH volumes (14.3 [8.0-39.4] vs. 6.7 [2.4-13.6] $\mathrm{mL} ; p=0.015)$, higher ICH scores (2 [2-4] vs. $1[0-3] ; p=0.035)$ and higher INR values (1.14 [1.03$1.31]$ vs. 1.01 [0.97-1.09]; $p=0.032)$. Urothelial cancer patients had more often a prior ischemic stroke $(4 / 5$ [80.0\%] vs. $14 / 78$ [17.9\%], $p=0.007)$.

\section{Outcome of ICH Patients with Systemic Cancer}

In the unadjusted analysis (Table 1), ICH patients with and without cancer showed no significant differences in mortality, or short- and long-term outcome. To account for confounders in baseline characteristics (age, gender, renal dysfunction, ICH volume, and NIHSS; Table 1), we performed PS matching, after which the PS-matched cohorts were evenly balanced in terms of demographics, comorbidities, admission status, and ICH volume (online suppl. Table 3).

Functional outcome data at discharge, at 3 months, and at 12 months are provided in Figure 1. Regarding mortality, there were no significant differences in the proportion of patients with in-hospital mortality $(18 / 83$ [21.7\%] vs. 36/161 [22.4\%]; $p=0.904)$, short-term mortality (33/81 [40.7\%] vs. 55/158 [34.8\%]; $p=0.368)$, and long-term mortality (39/78 [50.0\%] vs. 70/150 [46.7\%]; $p=0.633$ ). Among ICH patients with and without cancer, there were no significant differences in the proportion of patients with favorable outcome at discharge $(\mathrm{mRS}=0-3$ : $18 / 83$ [21.7\%] vs. $41 / 161$ [25.5\%]; $p=0.514)$, at 3 months ( $\mathrm{mRS}=0-3: 28 / 81$ [34.6\%] vs. $52 / 158$ [32.9\%]; $p=0.797)$ and at 12 months $(\mathrm{mRS}=0-3: 25 / 78$ [32.1\%] vs. 53/150 [35.3\%]; $p=0.620)$.

Kaplan-Meier survival curves are provided in Figure 2. Mortality analysis over a 12-month follow-up period by Log Rank $(p=0.724)$, Breslow $(p=0.832)$, and TaroneWare $(p=0.776)$ testing showed no significant difference in mortality between propensity-score-matched ICH patients with and without cancer (Fig. 2). Sub-analysis of ICH cancer-patients with active versus non-active cancer (online suppl. Fig. 1,2) and also sub-analysis of deep and lobar ICH location for patients with and without cancer (online suppl. Fig. 3, 4) revealed no significant differences in mortality or functional outcome.

\section{Discussion}

This study for the first time thoroughly analyzed the prevalence, types, and clinical characteristics of concomitant cancer diseases in a large cohort of ICH patients. We 
Table 1. Admission, in-hospital, and outcome characteristics of ICH patients with and without cancer

\begin{tabular}{|c|c|c|c|}
\hline Overall patients with ICH $(n=973)$ & $\begin{array}{l}\text { ICH without cancer } \\
(n=890)\end{array}$ & $\begin{array}{l}\text { ICH with cancer } \\
(n=83)\end{array}$ & $p$ value \\
\hline Age, years & $72(63-80)$ & $77(70-82)$ & 0.002 \\
\hline Gender, female & $419(47.1)$ & $30(36.1)$ & 0.056 \\
\hline \multicolumn{4}{|l|}{ Prior comorbidities } \\
\hline Premorbid mRS & $1(0-2)$ & $1(0-2)$ & 0.469 \\
\hline Hypertension & $730(82.0)$ & $70(84.3)$ & 0.598 \\
\hline Diabetes mellitus & $239(26.9)$ & $22(26.5)$ & 0.945 \\
\hline Renal impairment & $107(12.0)$ & $19(22.9)$ & 0.005 \\
\hline Liver impairment & $48(5.4)$ & $8(9.6)$ & 0.112 \\
\hline Prior ischemic stroke & $153(17.2)$ & $18(21.7)$ & 0.303 \\
\hline Prior hemorrhagic stroke & $82(9.2)$ & $6(7.2)$ & 0.547 \\
\hline Antiplatelet medication & $272(30.6)$ & $22(26.5)$ & 0.442 \\
\hline Oral anticoagulation & $186(20.9)$ & $19(22.9)$ & 0.670 \\
\hline \multicolumn{4}{|l|}{ Admission status } \\
\hline Glasgow Coma Scale & $13(5-15)$ & $13(10-15)$ & 0.137 \\
\hline NIHSS & $14(5-26)$ & $11(4-19)$ & 0.054 \\
\hline ICH score & $2(1-3)$ & $1(0-3)$ & 0.203 \\
\hline \multicolumn{4}{|l|}{ Imaging characteristics } \\
\hline Initial ICH volume, $\mathrm{mL}$ & $15.3(5.4-42.9)$ & $10.1(4.8-24.3)$ & 0.017 \\
\hline Intraventricular hemorrhage & $433(48.7)$ & $41(49.4)$ & 0.897 \\
\hline Deep & $419(47.1)$ & $37(44.6)$ & 0.662 \\
\hline Lobar & $393(44.2)$ & $40(48.2)$ & 0.479 \\
\hline Cerebellar & $62(7.0)$ & $6(7.2)$ & 0.928 \\
\hline Brainstem & $50(5.6)$ & $2(2.4)$ & 0.307 \\
\hline Hematoma growth & $80(9.0)$ & $9(10.8)$ & 0.575 \\
\hline Time from first to follow-up imaging, $\mathrm{h}$ & $21.0(13.0-30.0)$ & $23.0(16.0-35.5)$ & 0.310 \\
\hline \multicolumn{4}{|l|}{ Initial laboratory values } \\
\hline Thrombocytes, $10^{3} / \mu \mathrm{L}$ & $222.00(182.00-268.50)$ & $216.50(156.75-267.50)$ & 0.552 \\
\hline Leucocytes, $10^{3} / \mu \mathrm{L}$ & $9.07(7.07-11.64)$ & $8.18(6.18-11.29)$ & 0.115 \\
\hline $\mathrm{CRP}, \mathrm{nmol} / \mathrm{L}$ & $380.96(133.34-933.35)$ & $390.48(161.91-780.97)$ & 0.862 \\
\hline Creatinine, $\mu \mathrm{mol} / \mathrm{L}$ & $77.79(63.65-95.69)$ & $90.17(65.86-113.15)$ & 0.006 \\
\hline Troponin, ng/mL & $0.02(0.01-0.03)$ & $0.01(0.01-0.04)$ & 0.578 \\
\hline \multicolumn{4}{|l|}{ Clinical parameters during hospital stay } \\
\hline Length of stay, day & $10.0(5.0-17.0)$ & $10.0(6.0-16.0)$ & 0.713 \\
\hline MAP at admission, $\mathrm{mm} \mathrm{Hg}$ & $116.6(100.3-133.3)$ & $114.0(103.3-132.0)$ & 0.977 \\
\hline Mechanical ventilation & $380(42.7)$ & $27(32.5)$ & 0.073 \\
\hline External ventricular drain & $251(28.2)$ & $21(25.3)$ & 0.573 \\
\hline \multicolumn{4}{|l|}{ Complications } \\
\hline Sepsis & $160(18.0)$ & $19(22.9)$ & 0.269 \\
\hline Pneumonia & $306(34.4)$ & $29(34.9)$ & 0.919 \\
\hline Urinary tract infection & $83(9.3)$ & $6(7.2)$ & 0.526 \\
\hline \multicolumn{4}{|l|}{ Outcome } \\
\hline In-hospital mortality & $213(23.9)$ & $18(21.7)$ & 0.646 \\
\hline mRS 3 months $0-3$ & $289 / 872(33.1)$ & $28 / 81(34.6)$ & 0.794 \\
\hline mRS 12 months $0-3$ & $287 / 813(35.3)$ & $25 / 78(32.1)$ & 0.565 \\
\hline 1-Year mortality & $358 / 813(44.0)$ & $39 / 78(50.0)$ & 0.311 \\
\hline
\end{tabular}

Values are median (IQR) or $n(\%)$.

IQR, interquartile range; mRS, modified Rankin Scale; NIHSS, National Institutes of Health Stroke Scale; $\mathrm{ICH}$, intracerebral hemorrhage; hematoma growth defined as volume increase $>33 \%$ on follow-up imaging; INR, international normalized ratio; aPTT, activated partial thromboplastin time; CRP, C-reactive protein; MAP, mean arterial pressure. 


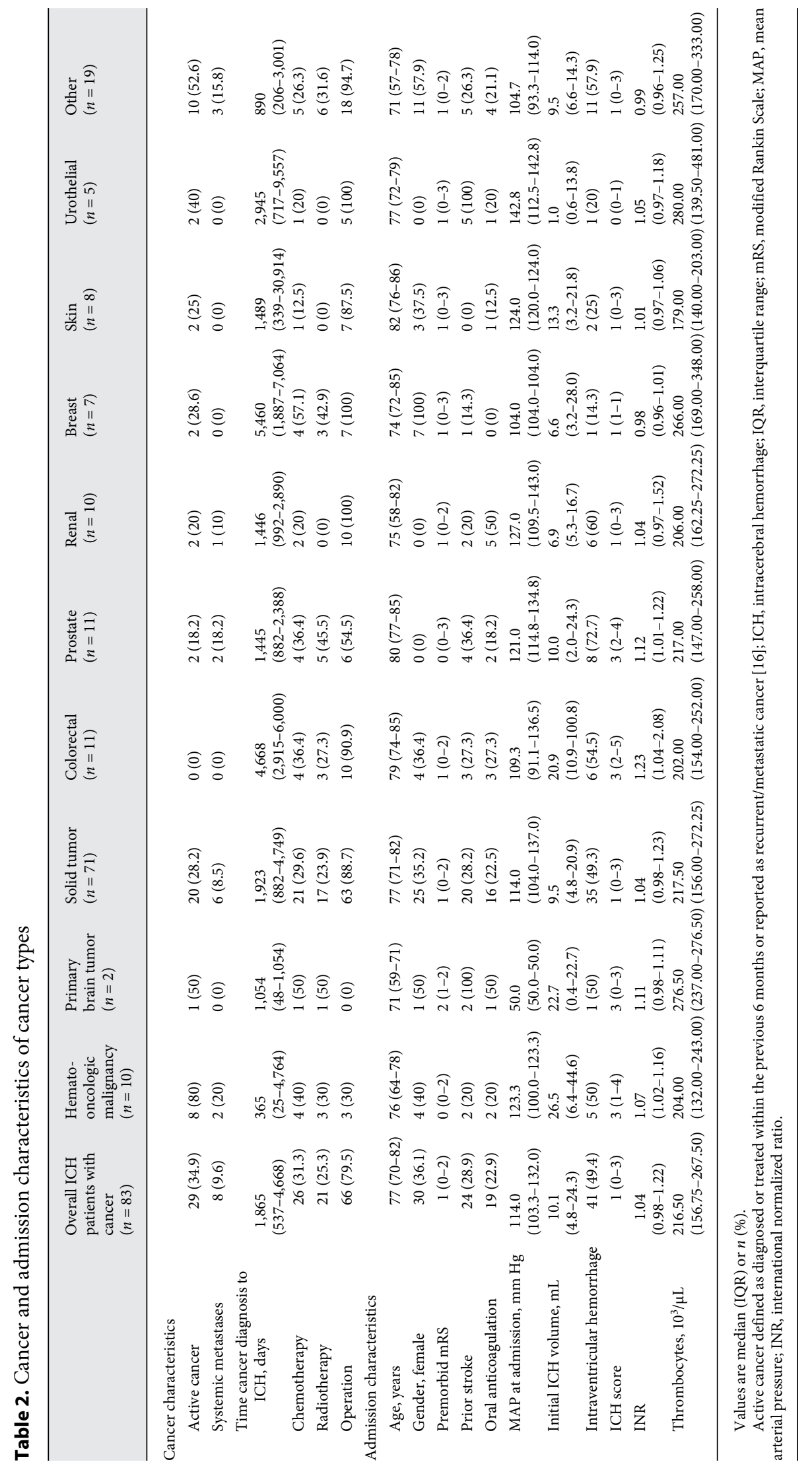


Fig. 1. Distribution of functional outcome (modified Rankin Scale) of ICH patients with cancer and PS-matched (age, gender, prior renal failure, NIHSS, ICH volume and ventilation) cohort without cancer. a Discharge outcome; b Short-term outcome (3 months); c Long-term outcome (12 months); mRS = modified Rankin score; scale: 0-6; from no deficit to death. The difference between favorable (mRS = $0-3$ ) and unfavorable (mRS $=4-6$ ) functional outcome is illustrated by a bold line and $p$ values are provided for comparison of patients with and without cancer.

Fig. 2. Kaplan-Meier survival curve from index ICH until 1-year follow-up in patients with cancer $(n=83)$ and PS-matched (age, gender, prior renal failure, NIHSS, ICH volume and ventilation) cohort without cancer $(n=161)$.

Intracerebral Hemorrhage in Cancer Patients
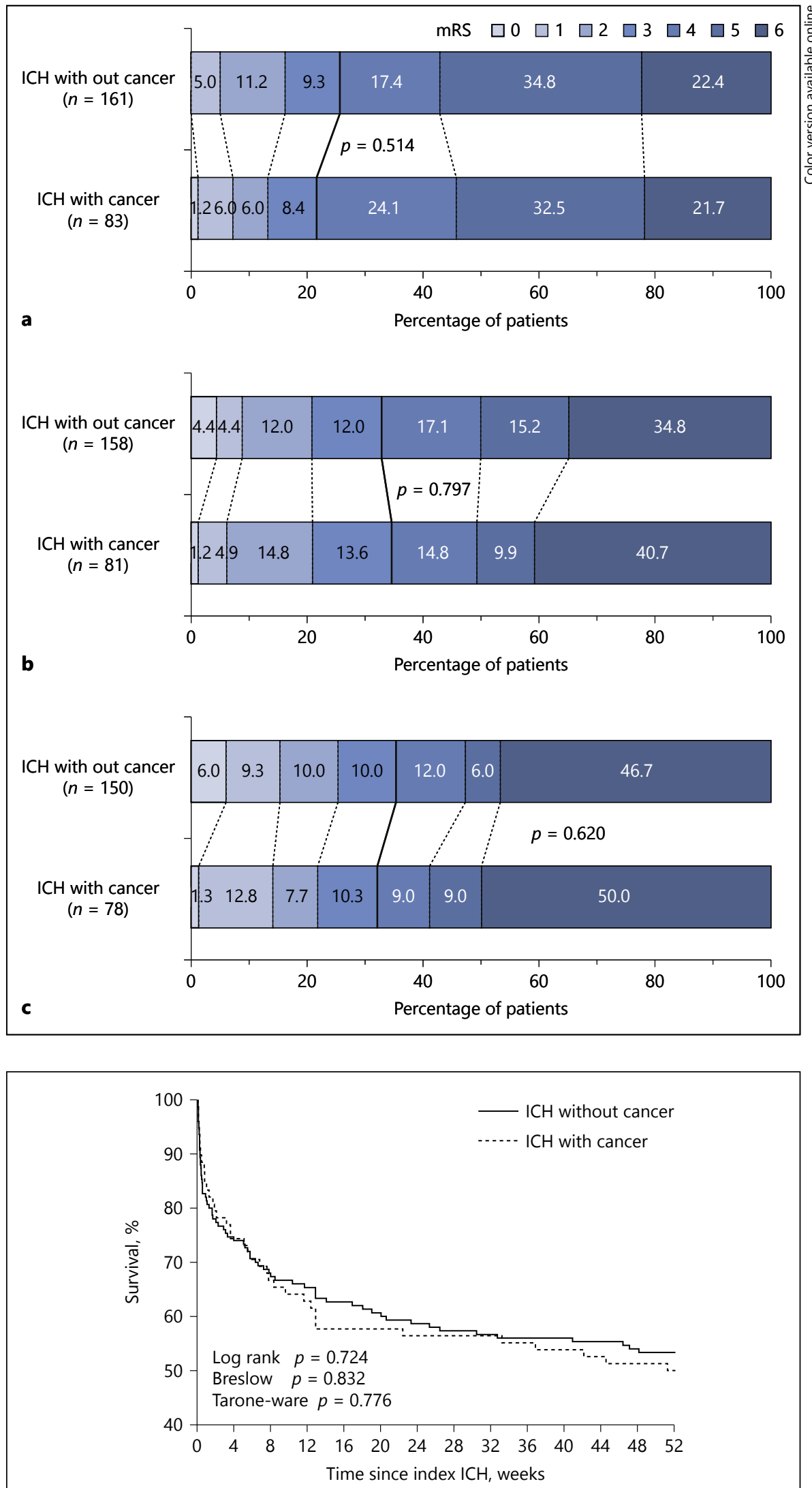

Cerebrovasc Dis 2017;44:186-194 
verified that ICH patients with concomitant cancer were older; however, we also showed smaller ICH volumes resulting in similar rates of mortality and unfavorable functional outcome compared to ICH patients without cancer. Using PS-matching, we demonstrated that both mortality and functional outcome do not significantly differ among ICH patients with and without cancer over a period of 12 months after ICH. Two important aspects deserve attention.

First, while it is not surprising that $\mathrm{ICH}$ patients with cancer were older than ICH patients without cancer [5], the fact that $\mathrm{ICH}$ volumes are smaller in concomitant cancer is novel. The complex interaction with the coagulation system and a prothrombotic status, evident up to many years after cancer diagnosis [27], represents a possible pathophysiological explanation [28, 29]. In line with this consideration, urothelial cancer patients in our study tended to have smaller ICH volumes consistent with previous studies demonstrating an increased risk of thrombotic events based on a prothrombotic status [27]. Further supportive, colorectal cancer patients showed larger ICH volumes, a finding that is possibly linked to surgery-based, impaired vitamin-K metabolism resulting in higher INR values [30, 31]. This aspect draws specific attention to optimally handle coagulation measures in the acute phase of ICH in colorectal cancer patients to minimize risk of hematoma enlargement [24].

Second, as demonstrated here, functional long-term outcome after ICH is not significantly impacted by concomitant cancer diagnosis. This finding harbors a significant clinical implication, as stroke physicians usually negatively stigmatize ICH patients with concomitant cancer. This intuitive feeling was recently supported by a registry database study reporting on higher mortality and less favorable outcome of ICH cancer patients at the time of hospital discharge [11]. However, this study was solely based on diagnosis codes and lacked most relevant clinical data (Glasgow Coma Scale, NIHSS, ICH volume, cancer details). Further significant shortcomings that - in the opinion of the authors of this study - undermine the conclusion of the manuscript refer to insufficient statistical corrections for imbalances of baseline characteristics [11]. In fact, our present study establishes no differences regarding both mortality and functional outcome over a one-year follow-up period among ICH patients with and without concomitant cancer. After adjusting for imbalances in baseline characteristics, ICH patients with cancer were more frequently affected by sepsis. Yet accounting for sepsis would rather benefit the cancer patient group and this therefore supports the conclusion of our study. A possible reason why an additional cancer diagnosis does not impact long-term prognosis after ICH relates to the severity of the bleeding itself, as demonstrated previously [3, 24, 32-34]. Therefore, the intuitive prognostication that ICH patients with cancer show worse outcomes needs a strong counterbalance to avoid early treatment restrictions and thus self-fulfilling prophecies $[12,35]$.

This study has certain strengths, such as the large sample size with reliable clinical data and a prospectively assessed 12 months follow-up period as well as the status of our department as a neurovascular care center including ICH patients with and without cancer in the hospital catchment area. Nevertheless, this is a single-center study. The numbers of patients with specific cancer types were limited; hence, conclusions from sub-analyses and multiple comparisons leave room for controversy. Further, on the one hand, end-stage palliative cancer patients treated at Oncology Departments or hospices and receiving comfort care only may have been missed out by our selection approach. On the other hand, in our included patients, we did not apply a standardized cancer-screening protocol for occult cancer and that is why some cancer patients potentially were missed, resulting in residual selection bias. Considering ICH etiology, there were no fixed time points for MRI imaging after ICH resorption and stroke recurrence was not assessed due to our study design. Yet, given the equal distribution of functional outcome and mortality over the one-year follow-up including subanalysis for ICH location, no essential imbalances ought to be present among both groups. Finally, we approached the field by studying all ICH patients and their eventual cancer co-diagnosis, instead of investigating ICH incidence among all cancer patients at our center, and that is why we do not have those patients as reference.

In conclusion, our study indicates that there are no relevant differences between ICH patients with and without cancer in terms of mortality and functional outcome. This finding may help physicians in the clinical management of ICH by avoiding unjustified care restrictions in ICH patients with concomitant cancer.

\section{Acknowledgment}

We thank Dr. Petra Burkardt (Erlangen University hospital, Germany) for helping with data management. 


\section{Disclosure Statement}

The authors have no conflicts of interest to disclose.

\section{Funding Source}

This study was partially funded by the ELAN program (12-0104-1; FSt56610036) of the Friedrich-Alexander University Erlangen-Nuremberg, Germany.

\section{Author Contribution}

M.I.S. and H.B.H. designed the study and wrote the manuscript. M.I.S, J.A.S., J.H., A.G.-J., D.M., and V.D.B. obtained clinical data by reviewing institutional databases and the patients' medical charts. P.H., H.L., and T.S. obtained and analyzed radiological data. S.T.G. and J.B.K. obtained functional outcome data and performed statistical analyses. S.S. critically revised the manuscript. All authors have read the manuscript, agreed with the contents, and approved of the final version of the manuscript.

\section{References}

1 GBD 2015 DALYs and HALE Collaborators: Global, regional, and national disability-adjusted life-years (DALYs) for 315 diseases and injuries and healthy life expectancy (HALE), 1990-2015: a systematic analysis for the Global Burden of Disease Study 2015. Lancet 2016; 388:1603-1658.

2 Howard G, Goff DC: Population shifts and the future of stroke: forecasts of the future burden of stroke. Ann N Y Acad Sci 2012; 1268:14-20.

3 van Asch CJ, Luitse MJ, Rinkel GJ, van der Tweel I, Algra A, Klijn CJ: Incidence, case fatality, and functional outcome of intracerebral haemorrhage over time, according to age, sex, and ethnic origin: a systematic review and meta-analysis. Lancet Neurol 2010;9:167176.

4 GBD 2015 Mortality and Causes of Death Collaborators: Global, regional, and national life expectancy, all-cause mortality, and cause-specific mortality for 249 causes of death, 1980-2015: a systematic analysis for the Global Burden of Disease Study 2015. Lancet 2016;388:1459-1544.

5 Smith BD, Smith GL, Hurria A, Hortobagyi GN, Buchholz TA: Future of cancer incidence in the United States: burdens upon an aging, changing nation. J Clin Oncol 2009;27:27582765.

6 Reulen RC, Winter DL, Frobisher C, Lancashire ER, Stiller CA, Jenney ME, Skinner R, Stevens MC, Hawkins MM: Long-term causespecific mortality among survivors of childhood cancer. Jama 2010;304:172-179.

7 Navi BB, Singer S, Merkler AE, Cheng NT, Stone JB, Kamel H, Iadecola C, Elkind MS, DeAngelis LM: Recurrent thromboembolic events after ischemic stroke in patients with cancer. Neurology 2014;83:26-33.

8 Qureshi AI, Malik AA, Saeed O, Adil MM, Rodriguez GJ, Suri MF: Incident cancer in a cohort of 3,247 cancer diagnosis free ischemic stroke patients. Cerebrovasc Dis 2015;39: 262-268.

9 Navi BB, Reichman JS, Berlin D, Reiner AS, Panageas KS, Segal AZ, DeAngelis LM: Intracerebral and subarachnoid hemorrhage in patients with cancer. Neurology 2010;74:494501 .
10 Ryu JA, Lee D, Yang JH, Chung CR, Park CM, Suh GY, Jeon K: Spontaneous intracranial haemorrhage in critically ill patients with malignancies. Support Care Cancer 2016;24: 2971-2978.

11 Murthy SB, Shastri A, Merkler AE, Hanley DF, Ziai WC, Fink ME, Iadecola C, Kamel H, Navi BB: Intracerebral hemorrhage outcomes in patients with systemic cancer. J Stroke Cerebrovasc Dis 2016;25:2918-2924.

12 Becker KJ, Baxter AB, Cohen WA, Bybee HM, Tirschwell DL, Newell DW, Winn HR, Longstreth WT Jr: Withdrawal of support in intracerebral hemorrhage may lead to self-fulfilling prophecies. Neurology 2001;56:766-772.

13 van Swieten JC, Koudstaal PJ, Visser MC, Schouten HJ, van Gijn J: Interobserver agreement for the assessment of handicap in stroke patients. Stroke 1988;19:604-607.

14 Stevens PE, Levin A: Evaluation and management of chronic kidney disease: synopsis of the kidney disease: improving global outcomes 2012 clinical practice guideline. Ann Intern Med 2013;158:825-830.

15 Pisters R, Lane DA, Nieuwlaat R, de Vos CB, Crijns HJ, Lip GY: A novel user-friendly score (HAS-BLED) to assess 1-year risk of major bleeding in patients with atrial fibrillation: the Euro Heart Survey. Chest 2010;138:10931100.

16 Lee AY, Levine MN, Baker RI, Bowden C, Kakkar AK, Prins M, Rickles FR, Julian JA, Haley S, Kovacs MJ, Gent M: Low-molecularweight heparin versus a coumarin for the prevention of recurrent venous thromboembolism in patients with cancer. $\mathrm{N}$ Engl J Med 2003;349:146-153.

17 Qureshi AI, Palesch YY, Barsan WG, Hanley DF, Hsu CY, Martin RL, Moy CS, Silbergleit R, Steiner T, Suarez JI, Toyoda K, Wang Y, Yamamoto H, Yoon BW: Intensive bloodpressure lowering in patients with acute cerebral hemorrhage. N Engl J Med 2016;375: 1033-1043.

18 Ziai WC, Tuhrim S, Lane K, McBee N, Lees K, Dawson J, Butcher K, Vespa P, Wright DW, Keyl PM, Mendelow AD, Kase C, Wijman C, Lapointe M, John S, Thompson R, Thompson C, Mayo S, Reilly P, Janis S, Awad I, Hanley DF: A multicenter, randomized, double- blinded, placebo-controlled phase III study of Clot Lysis Evaluation of Accelerated Resolution of Intraventricular Hemorrhage (CLEAR III). Int J Stroke 2014;9:536-542.

19 Banks JL, Marotta CA: Outcomes validity and reliability of the modified Rankin scale: implications for stroke clinical trials: a literature review and synthesis. Stroke 2007;38:10911096.

20 Kothari RU, Brott T, Broderick JP, Barsan WG, Sauerbeck LR, Zuccarello M, Khoury J: The ABCs of measuring intracerebral hemorrhage volumes. Stroke 1996;27:1304-1305.

21 Huttner HB, Steiner T, Hartmann M, Kohrmann M, Juettler E, Mueller S, Wikner J, Meyding-Lamade U, Schramm P, Schwab S, Schellinger PD: Comparison of $\mathrm{ABC} / 2$ estimation technique to computer-assisted planimetric analysis in warfarin-related intracerebral parenchymal hemorrhage. Stroke 2006; 37:404-408.

22 Burgess RE, Warach S, Schaewe TJ, Copenhaver BR, Alger JR, Vespa P, Martin N, Saver JL, Kidwell CS: Development and validation of a simple conversion model for comparison of intracerebral hemorrhage volumes measured on CT and gradient recalled echo MRI. Stroke 2008;39:2017-2020.

23 Brott T, Broderick J, Kothari R, Barsan W, Tomsick T, Sauerbeck L, Spilker J, Duldner J, Khoury J: Early hemorrhage growth in patients with intracerebral hemorrhage. Stroke 1997;28:1-5.

24 Kuramatsu JB, Gerner ST, Schellinger PD, Glahn J, Endres M, Sobesky J, Flechsenhar J, Neugebauer H, Juttler E, Grau A, Palm F, Rother J, Michels P, Hamann GF, Huwel J, Hagemann G, Barber B, Terborg C, Trostdorf F, Bazner H, Roth A, Wohrle J, Keller M, Schwarz M, Reimann G, Volkmann J, Mullges W, Kraft P, Classen J, Hobohm C, Horn M, Milewski A, Reichmann H, Schneider H, Schimmel E, Fink GR, Dohmen C, Stetefeld H, Witte O, Gunther A, Neumann-Haefelin T, Racs AE, Nueckel M, Erbguth F, Kloska SP, Dorfler A, Kohrmann M, Schwab S, Huttner HB: Anticoagulant reversal, blood pressure levels, and anticoagulant resumption in patients with anticoagulation-related intracerebral hemorrhage. JAMA 2015;313:824-836. 
25 Drake C, Fisher L: Prognostic models and the propensity score. Int J Epidemiol 1995;24: 183-187.

26 Forti P, Maioli F, Domenico Spampinato M, Barbara C, Nativio V, Coveri M, Zoli M, Simonetti L, Di Pasquale G, Procaccianti G: The effect of age on characteristics and mortality of intracerebral hemorrhage in the oldest-old. Cerebrovasc Dis 2016;42:485-492.

27 Zoller B, Ji J, Sundquist J, Sundquist K: Risk of haemorrhagic and ischaemic stroke in patients with cancer: a nationwide follow-up study from Sweden. Eur J Cancer 2012;48: 1875-1883.

28 Khasraw M, Posner JB: Neurological complications of systemic cancer. Lancet Neurol 2010;9:1214-1227.
29 Dearborn JL, Urrutia VC, Zeiler SR: Stroke and cancer- a complicated relationship. J Neurol Transl Neurosci 2014;2:1039.

30 Shearer MJ: Vitamin K in parenteral nutrition. Gastroenterology 2009;137:S105-S118.

31 Dibaise JK, Young RJ, Vanderhoof JA: Enteric microbial flora, bacterial overgrowth, and short-bowel syndrome. Clin Gastroenterol Hepatol 2006;4:11-20.

32 Kuramatsu JB, Gerner ST, Lucking H, Kloska SP, Schellinger PD, Kohrmann M, Huttner HB: Anemia is an independent prognostic factor in intracerebral hemorrhage: an observational cohort study. Crit Care 2013;17:R148.
33 Beuscher VD, Kuramatsu JB, Gerner ST, Kohn J, Lucking H, Kloska SP, Huttner HB: Functional long-term outcome after left- versus right-sided intracerebral hemorrhage. Cerebrovasc Dis 2017;43:117-123.

34 Giede-Jeppe A, Bobinger T, Gerner ST, Sembill JA, Sprugel MI, Beuscher VD, Lucking H, Hoelter P, Kuramatsu JB, Huttner HB: Neutrophil-to-lymphocyte ratio is an independent predictor for in-hospital mortality in spontaneous intracerebral hemorrhage. Cerebrovasc Dis 2017;44:26-34.

35 Zahuranec DB, Brown DL, Lisabeth LD, Gonzales NR, Longwell PJ, Smith MA, Garcia NM, Morgenstern LB: Early care limitations independently predict mortality after intracerebral hemorrhage. Neurology 2007;68:1651-1657. 